\title{
Nanostructured polymeric system based of cashew gum for oral admnistration of insulin
}

\author{
Eliadna de Lemos Vasconcelos Silva ${ }^{1}$, Antônia Carla de Jesus Oliveira ${ }^{1}$, \\ Edson Cavalcanti Silva-Filho ${ }^{2}$, António José Ribeiro ${ }^{3}$, \\ Francisco Veiga ${ }^{3}$, Monica Felts de La Roca Soares ${ }^{1}$, \\ Almir Gonçalves Wanderley ${ }^{1}$, José Lamartine Soares-Sobrinho ${ }^{1}$
}

\footnotetext{
${ }^{1}$ Federal University of Pernambuco - UFPE, CP: 50740-521, Recife, Pernambuco, Brazil.

${ }^{2}$ Federal University of Piauí - UFPI, CP: 640449-550, Terezina, Piauí, Brazil.

${ }^{3}$ Faculty of Pharmacy of University of Coimbra - UC, CP: 3000-548, Coimbra, Beira Litoral, Portugal. e-mail: adnalemos1989@hotmail.com, edsonfilho@ufpi.edu.br, carlinha_nere@hotmail.com,mfs.ufpe@gmail.com, almirgw.wanderley@gmail.com, joselamartine@hotmail.com, aribeiro@ff.uc.pt,fveiga@ci.uc.pt
}

\begin{abstract}
The subcutaneous administration of insulin has been the treatment of millions of diabetics in the world. However, for such via insulin is invasive and not mimics the physiological action causing side effects. The oral route would be the most physiological and comfortable option, but the oral bioavailability of insulin is low by proteolytic activity and reduced permeability of the gastrointestinal tract. The aim of the study was to develop a nanostructured system integrating biomaterials for oral insulin delivery. Cashew gum (CG) is a polysaccharide extracted from the exudate of the plant Anacardium occidentale. It is a biopolymer composed of simple sugars and glucuronic acid and it can be used in nanostructured systems for the incorporation of molecules. The exudate was isolated, dissolved in water, filtered, precipitated in ethanol and purified. The CG was characterized by infrared spectroscopy and molecular weight by size exclusion chromatography. Nanoparticles were prepared through ionotropic gelation integrating cashew gum, dextran sulfate and poloxamer containing insulin stabilized with chitosan, poly(ethyleneglycol) and coated with albumin. The particles were analyzed for particle size, zeta potential and insulin entrapment efficiency. The FTIR spectrum for CG showed a band at $3395 \mathrm{~cm}^{-1}$ due to the stretching vibration of $\mathrm{O}-\mathrm{H}$, a band at $2926 \mathrm{~cm}^{-1}$ of C-H vibrations; absorption at $1639 \mathrm{~cm}^{-1}$ of O-H type from bound water molecules and bands at 1143,1073 and $1024 \mathrm{~cm}^{-1} \mathrm{due}^{-}$ vibrations of the $\mathrm{C}-\mathrm{O}-\mathrm{C}$ from glycosidic bonds and $\mathrm{O}-\mathrm{H}$ of alcohols. The peak molar mass of GC was $2.35 \times$ $10^{4} \mathrm{~g} / \mathrm{mol}$. The particles had a size of $156 \mathrm{~nm}$ and after coating, size of $5387 \mathrm{~nm}$ with $92 \%$ insulin entrapment efficiency and zeta potential of $-51 \mathrm{mV}$ indicating electrostatic stabilization. The results suggest an innovative cashew gum base system for oral insulin administration.
\end{abstract}

Keywords: Nanostructures, biomaterials, cashew gum, insulin, oral delivery.

\section{INTRODUCTION}

Diabetes mellitus is a metabolic disease that requires strict glycemic control to reduce its progression and complications; the therapy is based on the exogenous administration of insulin performed subcutaneously, however, in addition to being invasive and requiring several daily injections, administered insulin by this way does not mimic the physiological action of insulin causing side effects [1,2]. The oral route would be the most physiological and convenient for diabetics; however, because of this, insulin has low bioavailability due to high proteolytic activity, as well as reduced permeability of the fatty-intestinal tract $[3,4]$. Among the most promising approaches to oral insulin therapy are nanostructured biopolymers based on the incorporation of insulin into biocompatible, biodegradable and mucoadhesive nanoparticles that protect and promote the absorption of insulin into the gastrointestinal tract [5].

Cashew gum (CG) characterized as a polysaccharide, is a biopolymer from the Anacardium occidentale (cashew tree), with varied applications in the food, medical and pharmaceutical industries, and can be used as an encapsulating agent in active ingredient release systems. GC is composed of several simple sugars and guluronic acid anionic chains [6]. This polycrystalline block is capable of interacting selectively with multivalent cations forming small nuclei that are stabilized in nanoparticles after polyolefin poly-complexing 
with polyamines [7]. Chitosan is a cationic polymer that has amine groups in the structure responsible for conferring positive charge on the molecule, besides being biodegradable and biocompatible, it has mucoadhesive properties because it is able to interact ionically with negative charges present in the intestinal mucus and on the surface of the cells [8]. This interaction increases the time of permanence of the nanoparticles in the place favoring, consequently, greater absorption of the drug [9].

The incorporation of polyanions in nanostructured systems containing insulin, allows an increase of the electrostatic interactions, improving the efficiency of incorporation of the drug in the nanoparticles [10]. Dextran sulfate is a biodegradable, biocompatible, anionic polymer with a branched chain structure of anhydrous units grafted with free sulfate groups that interact with isolated ions such as calcium or with other cationic polymers promoting stability to interactions [7].

In addition to the use of polymers in the nanostructured system, stabilizers have also been used in this work. Poloxamer, a nonionic copolymer, is capable of conferring steric stabilization to the system by its amphiphilic nature [11], and poly(ethyleneglycol) (PEG), a non-toxic polyether capable of reducing the interaction between the particles conferring steric stabilization [12], besides it being mucoadhesive contributing to improve the transport of large proteins through the intestinal mucosa favoring the absorption [13].

In addition, insulin denaturation has been indicated as one of the causes of failure in the preparation of insulin delivery systems [14]. Therefore, albumin coating has been indicated to avoid degradation of insulin by proteases, preventing they can reach the insulin inside the nanoparticles, giving stability to the system in the stomach $[15,16]$.

The aim of the study was to develop a nanostructured system using cashew gum integrating biomaterials for oral insulin delivery, making the adhesion to the treatment more efficient and significantly improving the quality of life of the patients.

\section{MATERIALS AND METHODS}

\subsection{Materials}

The crude cashew gum was obtained from the natural exudate from trees in Parnaíba, Piauí, Brazil and the samples were purified by the method described by [17]. Low molecular weight chitosan (50 kDa), bovine serum albumin (BSA) and Poly(ethyleneglycol) 35000 (PEG 35000) were purchased from Sigma-Aldrich Chemie (France); Dextran sulfate sodium salt from Leuconostoc ssp., Poloxamer 188 (Lutrol@ F68, BASF, Ludwigshafen, Germany); Poly(ethyleneglycol) 4000 (PEG 4000) purchased from Fisher Scientific (UK); Calcium chloride (Riedel-de-Hae"n, Germany); 90\% lactic acid purchased from VWR BDH Prolabo (France); 99\% trifluoroacetic acid (TFA) and acetonitrile (LiChrosolv) were obtained from Sigma-Aldrich Co. (St Louis, MO, USA); Insulin 100 IU/ml (Actrapid®, Novo Nordisk A/S, Bagsværd, Denmark).

The chitosan was dissolved in $0.5 \%(\mathrm{v} / \mathrm{v})$ of lactic acid solution. The solutions were filtered through, Whatman, qualitative 1 , filter paper under vacuum.

\subsection{Purification and characterization of cashew gum}

CG was isolated from exudate from trees of the genus Anacardium occidentale L. and purified with sodium salt and precipitated in ethyl alcohol by the method described by Paula et al., 1998.

\subsubsection{FTIR spectroscopy analysis}

The polysaccharide obtained (CG) was characterized by infrared spectroscopy on an FT-IR PerkinElmer, spectrum 400, in the ATR module, in the range of 4000 to $700 \mathrm{~cm}^{-1}$.

\subsubsection{Proton nuclear magnetic resonance ( ${ }^{1} \mathrm{H}$ NMR)}

The CG sample was dissolved in deuterium oxide $\left(\mathrm{D}_{2} \mathrm{O}\right)$. The spectra were obtained in the Varian 400 vnmrs400 model, with temperature control at $50^{\circ} \mathrm{C}$.

\subsubsection{Size Exclusion Chromatography (SEC)}

To determine the molecular weight, the polymer was analyzed by a size exclusion chromatography (SEC) system equipped with an on-line degasser, a refractive index (RI) detector and a set of columns including a Shodex OHpak SB-G column protector and the OHpak SB-SB-802.5HQ and OHpak SB-804HQ columns. 
The polymers were eluted with a flow rate of $0.5 \mathrm{~mL} / \mathrm{min}$ with $0.1 \mathrm{M} \mathrm{Na} 2 \mathrm{SO} 4$ (aq); 1 wt\% acetic acid; $0.02 \% \mathrm{NaN} 3$ at $40{ }^{\circ} \mathrm{C}$. Prior to injection $(50 \mu \mathrm{L})$, the samples were filtered through a polytetrafluoroethylene (PTFE) membrane with a pore size of $0.45 \mu \mathrm{m}$. The system was calibrated with five narrow PEG standards and the molecular weight of polymers $(\mathrm{MnSEC})$ and $Ð(\mathrm{Mw} / \mathrm{Mn})$ were determined by conventional calibration using software clarity version 2.8.2.648.

\subsection{Preparation and characterization of the nanoparticles}

Nanoparticles were developed based on the methodology described by [7], with some modifications. Nanoparticles were prepared by complexation of biomaterials carrying opposite charges under controlled $\mathrm{pH}$ conditions. An aqueous solution of $0.2 \%(\mathrm{w} / \mathrm{v})$ cashew gum was prepared by stirring overnight. $0.02 \%(\mathrm{w} / \mathrm{v})$ dextran sulfate, $0.04 \%(\mathrm{w} / \mathrm{v})$ poloxamer 188 and $0.006 \%(\mathrm{w} / \mathrm{v})$ insulin was added and dissolved. Complexation involved the dropwise addition of aqueous solution of $0.2 \%(\mathrm{w} / \mathrm{v})$ calcium chloride, followed by a solution at $\mathrm{pH} 4.6$ containing $0.07 \%(\mathrm{w} / \mathrm{v})$ chitosan and $0.35 \%(\mathrm{w} / \mathrm{v})$ PEG 4000 for stabilization of nanoparticles. Followed by dropwise addition of $1 \%(\mathrm{w} / \mathrm{v})$ albumin solution. Nanoparticles were concentrated by dialysis using regenerated cellulose membrane with nominal dry weight of 100K MWCO (SnakeSkin Pleated Dialysis Tubing-Thermo Fisher Scientific Inc., USA) and dialysis solution of 10\% poly(ethyleneglycol) 35000 for 24 hours at $4{ }^{\circ} \mathrm{C}$. A formulation was prepared at room temperature under magnetic stirring at $800 \mathrm{rpm}$ for 40 min.

\subsubsection{Particle size and zeta potential analysis}

Particle size and zeta potential measurements were performed on Zetasizer Nano ZS (Malvern Instruments Ltd.). Surface charge was determined by laser doppler electrophoresis and measurements were carried out in a folded capillary electrophoresis cell. The size distribution was measured by dynamic light scattering (DLS) and represented by normalized intensity distribution. The measurements were performed in triplicate at $25^{\circ} \mathrm{C}$, with a detection angle of $90^{\circ}$. The results were presented as mean particle size distribution and zeta potential.

\subsubsection{Insulin entrapment efficiency}

Insulin entrapment efficiency was determined by the difference between the total amount of insulin used to prepare nanoparticles and the amount of free insulin per total amount of insulin. Nanoparticles containing insulin were separated from aqueous supernatant containing free insulin by centrifugation (10.000 rpm for 10 min at $4{ }^{\circ} \mathrm{C}$, and the amount of free insulin was determined in triplicate by high-performance liquid chromatography (HPLC).

\subsubsection{Insulin quantification}

Insulin was determinated according to the methodology validated by [10]. Insulin was analyzed by highperformance liquid chromatography (HPLC) using an LC-2010 HT HPLC system (Shimadzu, Japan) equipped with a quaternary pump, a UV detector set at $214 \mathrm{~nm}$, a reversed-phase X-Terra RP 18 column, 5 $\mu \mathrm{m}, 4.6 \times 250 \mathrm{~mm}$ (Waters, USA) and Purospher STAR RP-18 precolumn $5 \mu \mathrm{m}, 4$ x $4 \mathrm{~mm}$ (Merck KGa, Germany). The mobile phase consists of acetonotrile (A) and $0.1 \%$ trifluoroacetic acid (TFA) aqueous solution (B) operated in gradient mode at flow rate of $1.0 \mathrm{ml} \mathrm{min}^{-1}$ set to 30:70 (A:B), changed to 40:60 (A:B) in $5 \mathrm{~min}$ for elution over $5 \mathrm{~min}$, and changed to $30: 70(\mathrm{~A}: \mathrm{B})$ in $1 \mathrm{~min}$ for elution over $1 \mathrm{~min}$. The chromatograms were recorded and the peak area responses were measured using an automatic integrator.

\section{RESULTS AND DISCUSSION}

\subsection{Purification and characterization of cashew gum}

The cashew gum was characterized by infrared spectroscopy and the spectrum showed a band at $3395 \mathrm{~cm}^{-1}$ by $\mathrm{O}-\mathrm{H}$ stretching vibration, a band at $2926 \mathrm{~cm}^{-1}$ by C-H vibrations; absorption at $1639 \mathrm{~cm}^{-1}$ of O-H type from bound water molecules and bands at 1143,1073 and $1024 \mathrm{~cm}^{-1}$ due to the presence of C-O-C vibrations from glycosidic bonds and O-H of alcohols (Fig. 1) [18]. 


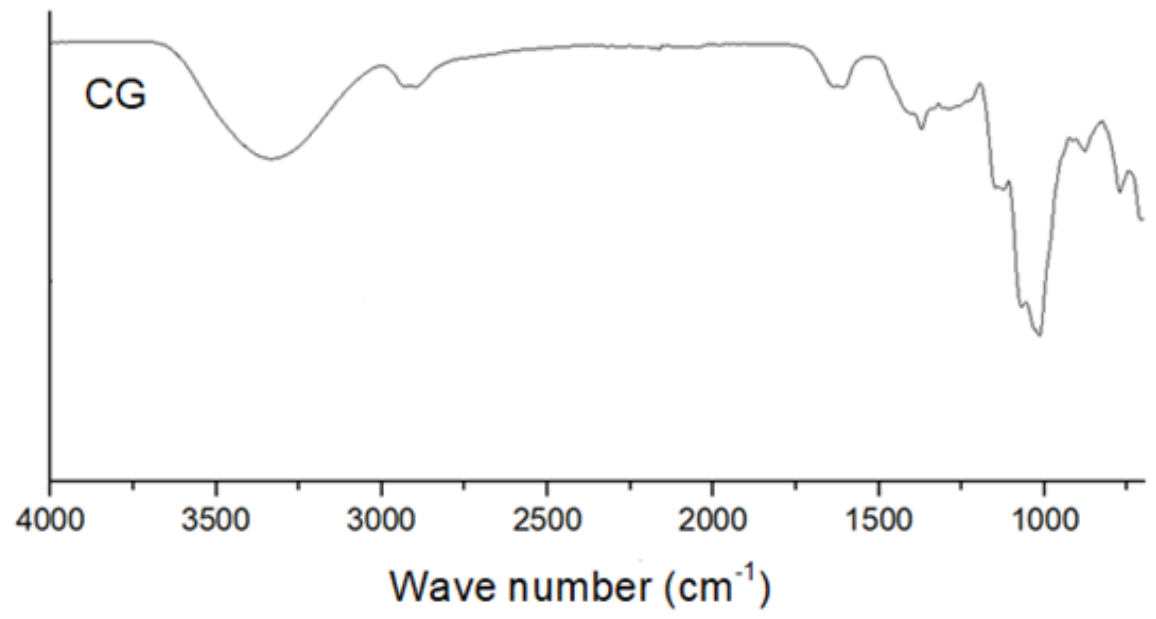

Figura 1: FTIR spectra for cashew gum.

The ${ }^{1} \mathrm{H}$ NMR spectrum for CG is shown in Fig. 2. The CG spectrum showed a signal at $1.1 \mathrm{ppm}$ due to the presence of $\mathrm{CH} 3$ of rhamnose and signals at $3.0-4.5$ ppm due to the presence of $\mathrm{OH}$ and $\mathrm{H}-1$ to $\mathrm{H}-6$ protons present in the polysaccharide $[18,19]$.

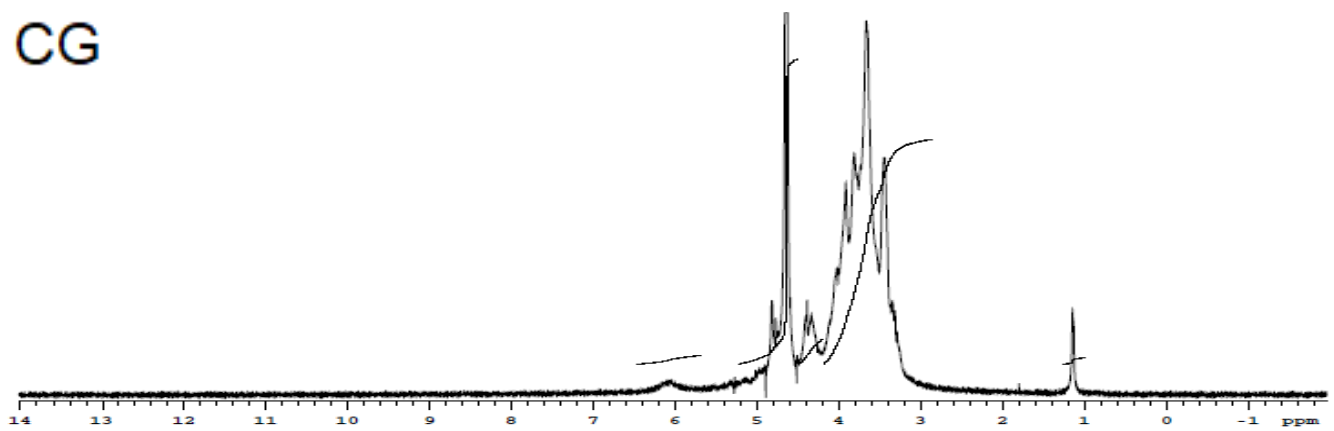

Figura 2: ${ }^{1} \mathrm{H}$ NMR spectra for the cashew gum.

The cashew gum presented molar mass of $2.35 \times 10^{4} \mathrm{~g} / \mathrm{mol}$. The molecular weight of CG was determined by the size exclusion chromatography technique using the molecular weight distribution characterization markers, $M n$ (mean molecular weight), $M w$ (mean molecular weight) and $Ð$ (polydispersity) calculated by the quotient $M w / M n$ (Table 1). The chromatogram from which these values were exported is presented in figure 7. During the process of purification of the material, it is of extreme importance that the treatments applied to the polysaccharide do not discharacterize it, guaranteeing the intact maintenance of its structure and/or average molar mass.

Tabela 2: Mean molecular weights (Mn and Mw) and polydispersity $(\nexists)$ of cashew gum.

\begin{tabular}{l|l|l}
\hline $\mathbf{M}_{n}$ & $\boldsymbol{M}_{\mathbf{W}}$ & $\boldsymbol{D}$ \\
\hline 19700 & 23500 & 1,20 \\
\hline
\end{tabular}




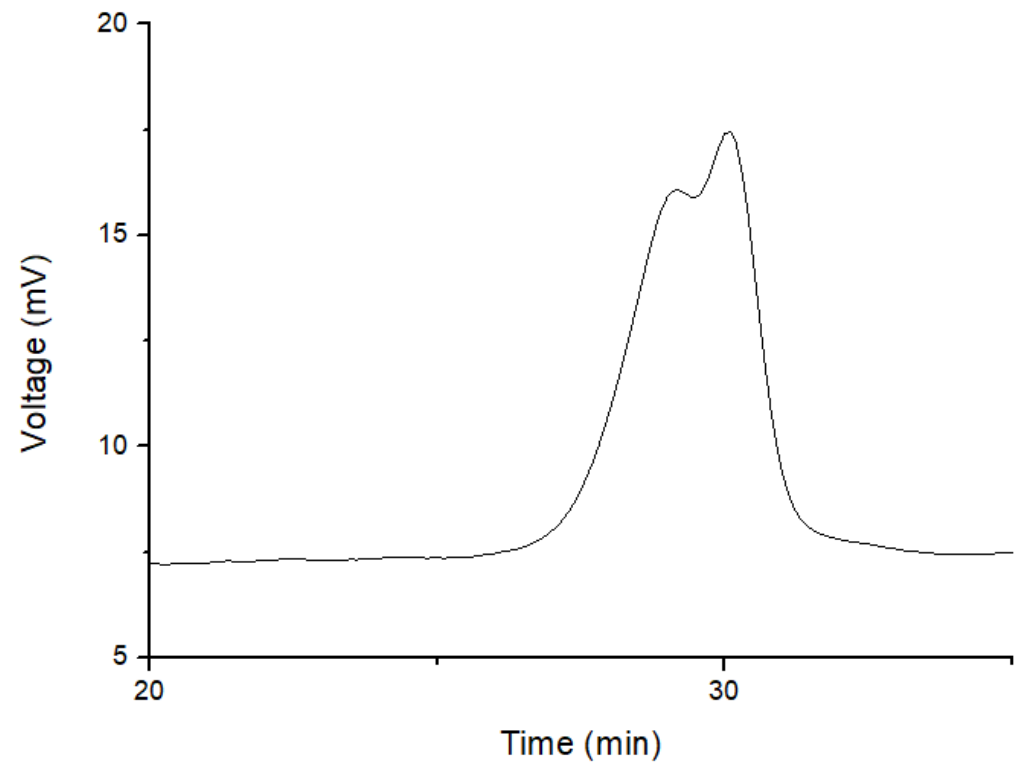

Figura 3: Chromatogram of the molecular mass of cashew gum.

Similar molar mass value was also observed by [20], where cashew gum showed a peak molar mass of $2.3 \times 10^{4} \mathrm{~g} / \mathrm{mol}$, corroborating the results.

\subsection{Preparation and characterization of nanoparticles}

The prepared nanoparticles formed a multilayer complex with the insulin protected and retained, containing the outermost layer of albumin. Polyelectrolyte complex nanoparticles were formed by interaction of opposite charges of biopolymers.

The mean uncoated particle size containing insulin determined by the dynamic light scattering was $156 \mathrm{~nm}$. After coating the particles had an average size of $522 \mathrm{~nm}$ and $5387 \mathrm{~nm}$, respectively, for chitosan and albumin coating.

The particle size is important for the assessment of gastrointestinal absorption [21, 22], because it influences the body distribution [23], mucoadhesion [24, 25] and drug release profile [26]. The particles had a particle size lower than the critical value reported in the literature indicating that they can be absorbed orally. The polydispersive index of coated and finished particles was 0.2 indicating good particle size distribution. The confirmation of the formation of nanoparticles was given by the presence of Tyndall effect, by the visualization of the opalescent suspension. The granulometric distribution of the nanospheres was unimodal as shown in figure 4 .

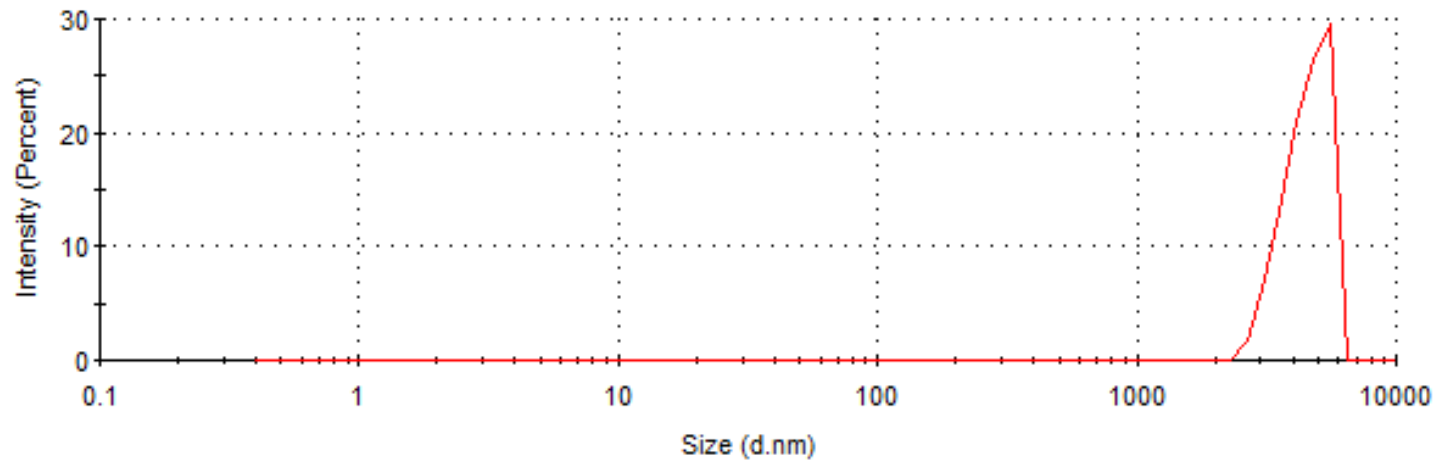

Figura 4: Particle size distribution (determined by DLS) of nanoparticles with insulin.

The increase of the nanoparticles resulting from the coating with chitosan was also described in algi- 
nate nanoparticles prepared by [27], where the coating with the chitosan contributed to the increase of the size of the alginate nucleus in relation to its initial diameter. The result of the albumin coating on particle size may be related to changes in the electrical state causing the particles to increase or shrink in size, depending on whether the electrical repulsions increase or decrease within the particles [28].

The zeta potential characterizes the global electric charge of the surface of a particle, determining the electrophoretic mobility of the particles that is measured by their velocity per unit of electric field that is applied on the dispersion of ions in the diluent with ionic force. The result of the zeta potential indicates the electrostatic stability of the NP with values greater than $30 \mathrm{mV}$ or less than $30 \mathrm{mV}$, related to nanoparticles with higher suspension stability and low tendency of aggregate formation [29].

The results show that the nanoparticles are negatively charged with zeta potential values of $-27 \mathrm{mV}$ for the uncoated nanoparticles. After coating with chitosan the particles had a surface charge of -6.8 and the coated and finished particles after the albumin coating presented a $-51 \mathrm{mV}$ loading indicating stable system [30]. Suspension stability, allows less formation of aggregate formation due to the high repulsive force between the particles [31]. The changes in the surface charges of the particles observed after the coatings confirm that the polyelectrolyte complexation occurred. The chitosan coating altered the surface charge of the particles, making it less negative, evidencing that the interaction with the chitosan occurred in fact and the change in the load after the albumin coating also confirms the efficiency of the interaction.

The albumin coating was added for protection of insulin against proteolytic enzymes from the gastric environment, improving the resistance of the nanoparticles in this medium. In alginate and dextran sulfate nanospheres containing insulin coated with chitosan and albumin, the second coating with albumin worked as a target for pepsin degradation by keeping the encapsulated insulin protected from proteolytic attack in the stomach and exposing the underlying layer of the coating with chitosan, allowing the nanospheres to exert mucoadhesive properties in the intestinal environment [32].

\subsubsection{Insulin entrapment efficiency}

The efficiency of insulin encapsulation is a measure of the amount of insulin entrapped and retained by the nanoparticle formulation. The value of insulin encapsulation efficiency was $92 \%$, higher than previously reported $(90 \%)$ by WOITISKI et al. [7], in alginate and dextran sulfate nanoespheres coated with chitosan and albumin.

Such results of high level of encapsulation indicate that there was an effective result in the formulation of the nanospheres with the cashew gum under the proposed conditions. The effect of $\mathrm{pH}$ on the components of the formulation may have contributed to the good result. Insulin has an isoelectric point at pH about 5.3, when the $\mathrm{pH}$ is above the isoelectric point, insulin has a negative charge and when it is below the point it has a positive charge. In the isoelectric point the hormone presents minimal solubility, since the lack of its total charge indicates that the molecules no longer repel, tending to agglutinate and precipitate [33].

In addition, the cashew gum, at $\mathrm{pH}$ less than 5.0, presents the carboxylic groups more ionizable, besides showing better rheological characteristics by the high viscosity [34,35]. Thus, strong electrostatic attractiveness can occur at the final $\mathrm{pH}$ of 4.6, providing high encapsulation efficiency of the oppositely charged insulin.

Calcium ions interacting with the glucuronic residues of cashew gum can establish ionic bridges of the negatively charged carboxylic residues with insulin, strengthening the interaction [27]. The inclusion of poloxamer 188 may also favor the efficiency of insulin encapsulation due to promoted steric stabilization [7].

\section{CONCLUSIONS}

In conclusion, cashew gum was successfully purified and characterized with results corroborating with the literature, with a molar mass of $2.35 \times 10^{4} \mathrm{~g} / \mathrm{mol}$. The particles shows a mean final size of $5387 \mathrm{~nm}$, after the coatings, it being below the critical value required for instestinal absorption and could then be absorbed by the oral route. The final zeta potential of the formulation $(-51 \mathrm{mV})$ indicated nanoparticles with high electrostatic stability. The polyelectrolyte complexation methodology applied with mild conditions for insulin and easy to perform procedures allowed the preparation of particles with $92 \%$ retention of insulin, being promising as a formulation for oral insulin administration using biopolymers. 


\section{ACKNOWLEDGEMENTS}

The authors acknowledge CNPq for a scholarship and financial aid.

\section{BIBLIOGRAPHY}

[1] BABIKER, A., DATTA, V., "Lipoatrophy with insulin analogues in type I diabetes", Archives of Disease Childhood, v. 96, pp. 101-102, 2010.

[2] CRYER, P. E., GERICH, J. E., "Glucose counterregulation, hypoglycemia, and intensive insulin therapy in diabetes mellitus", New England Journal Medicine, v. 313, pp. 232-241, 1985.

[3] OWENS, D. R., ZINMAN, B., BOLLI, G., “Alternative routes of insulin delivery”, Diabetic Medicine, v. 20, pp. 886-898, 2003.

[4] DELIE, F., BLANCO-PRIETO, M. J., "Polymeric particulates to improve oral bioavailability of peptide drugs", Molecules, v. 10, pp. 65-80, 2005.

[5] RIBEIRO, A., SEIÇA, R., VEIGA, F., Nanoparticles for Oral Delivery of Insulin. In Drug Delivery Systems: Advanced Technologies Potentially Applicable in Personalised Treatment, Molecules, 1 ed., Springer Netherlands, 2013.

[6] RIBEIRO, A. J., SOUZA, F. R. L., BEZERRA, J. M. N. A., et al., “Gums' based delivery systems: Review on cashew gum and its derivatives", Carbohydrate Polymers, v. 147, pp. 188-200, 2016.

[7] WOITISKI, C. B., NEUFELD, R. J., RIBEIRO, A. J., et al., "Colloidal Carrier integrating biomaterials for oral insulin delivery: Influence of component formulation on physicochemical and biological parameters", Acta Biomaterialia, v. 5, pp. 2475-2484, 2009.

[8] SCHIPPER, N.G., OLSSON, S., HOOGSTRAATE, J.A., "Chitosans as absorption enhancers for poorly absorbable drugs 2: Mechanism of absorption enhancement”, Pharmaceutical Research, v. 14, pp. 923-929, 1997.

[9] GEORGE, M., ABRAHAM, T.E., "Polyionic hydrocolloids for the intestinal delivery of protein drugs: alginate and chitosan-a review", Journal of Controlled Release, v. 114, pp. 1-14, 2006.

[10] SARMENTO, B., RIBEIRO, A. J., VEIGA, F., et al., "Development and validation of a rapid reversedphase HPLC method for the determination of insulin from nanoparticules systems", Biomedical Chromatography, v. 20, pp. 898-903, 2006.

[11] HIRSJARVI, S., PELTONEN, L., HIRVONEN, J., "Surface pressure measurements in particle interaction and stability studies of poly(lactic acid) nanoparticles", International Journal of Pharmaceutics, v. 348, pp. 153-60, 2008.

[12] TOBÍO, M., SÁNCHEZ, A., VILA, A., et al., "The role of PEG on the stability in digestive fluids and in vivo fate of PEG-PLA nanoparticles following oral administration", Colloids and Surfaces B: Biointerfaces, v. 18, pp. 315-23, 2000.

[13] VILA, A., SÁNCHEZ, M., TOBÍO, P., et al., "Design of biodegradable particles for protein delivery" Journal of Controlled Release, v. 78, pp. 15-24, 2002.

[14] NAKAMURA, K., MORISHITA, M., EHARA, J., et al., "Key functions in polymer carriers for intestinal absorption of insulin", International Journal of Pharmaceutics, v. 354, pp. 135-42, 2008.

[15] LÉVY, M-C., LÉVY, F. E., "Coating alginate beads with cross-linked biopolymers: a novel method based on a transacylation reaction”, Journal of Microencapsulation, v. 13, pp. 169-83, 1996.

[16] HURTEAUX, R., EDWARDS-LÉVY, F., LAURENT-MAQUIN, D., et al., "Coating alginate microspheres with a serum albumin-alginate membrane: application to the encapsulation of a peptide", European Journal of Pharmaceutical Sciences. v. 24, p.187-97, 2005.

[17] PAULA, R. C. M., HEATLEY, F., BUDD, P.M., "Composition of Anacardium occidentale exsudate polysaccharide”. Polymer International, v. 45, pp. 27-35, 1998.

[18] PITOMBEIRA, N. A. O., VERAS-NETO, J. G., SILVA, D. A., et al., "Self- assembled nanoparticles of acetylated cashew gum: Characterization and evaluation as potential drug carrier", Carbohydrate Polymers, v. 117, pp. 610-615, 2015.

[19] LIMA, M. R., PAULA, H. C. B., ABREU, F. O. M. S., et al., "Hydrophobization of cashew gum by acetylation mechanism andamphotericin B encapsulation", International Journal of Biological Macromolecules, v. 108, pp. 523-530, 2018. 
[20] NETO, E. D., MACIEL, J. D., CUNHA, P. L. R., "Preparation and Characterization of a Chemically Sulfated Cashew Gum Polysaccharide", Journal of the Brazilian Chemical Society, v. 22, pp. 1953-1960, 2011.

[21] NORRIS, D. A., PURI, N., SINKO, P. J., "Effect of physical barriers and properties on the oral absorption of particulates", Advanced Drug Delivery Reviews, v. 34, p. 135-154, 1998.

[22] SAEZ, A., GUZMÁN, M., MOLEPECERES, J., et al., "Freese-drying of polycaprolactone and poly (D,L-lactic-glycolic) nanoparticles induce minor particle size changes affecting the oral pharmacokinetics of loaded drugs", European Journal of Pharmaceutics and Biopharmaceutics, v. 50, pp. 379-387, 2000.

[23] JANI, P., HALBERT, G. W., LANGRIDGE, J., et al., "Nanoparticle uptake by rat gastrointestinal mucosa: quantitation and particles size dependency", Journal of Pharmacy and Pharmacology, v. 42, pp. 821$826,1990$.

[24] TAKEUCHI, H., YAMAMOTO, H., NIWA, T., et al., "Enteral absorption of insulin in rats from mucoadhesive chitosan-coated liposomes”, Pharmaceutical Research, v. 13, pp. 896-901, 1996.

[25] GOTO, M., MORISHITA, M., KAVIMANDAN, N., et al., "Gastrointestinal transit and mucoadhesive characteristics of complexation hydrogels in rats", Journal of Pharmaceutical Sciences, v. 95, pp.462-469, 2006.

[26] RITGER, P. L., PEPPAS, N. A., “A simple equation for description of solute release i. Fickian and nonfickian release from non-swellable devices in the form of slabs, spheres, cylinders or discs", Journal of Controlled Release, v. 5, pp. 23-36, 1987.

[27] SARMENTO, B., RIBEIRO, A., VEIGA, F., et al., "Insulin loaded nanoparticles are prepared by alginate ionotropic pre-gelation followed by chitosan polyelectrolyte complexation", Journal of Nanoscience and Nanotechnology, v. 7, pp. 1-9, 2007.

[28] THU, B., BRUHEIM, P., ESPEVIK, T., et al., "Alginate polycation microcapsules: I. Interaction between alginate and polycation", Biomaterials, v.17, p. 1031-40, 1996.

[29] BENITA, S., LEVY, M. Y., "Submicron emulsions as colloidal drug carriers for intravenous administration: comprehensive physicochemical characterization", Journal of Pharmaceutical Sciences, v. 82, pp. 1069-79, 1993.

[30] MOHANRAJ, V. J., CHEN, Y., "Nanoparticles-A review”, Tropical Journal of Pharmaceutical Research, v. 5, pp. 561-573, 2006.

[31] MAGENHEIM, B., BENITA, S., "Nanoparticle characterization: a comprehensive physicochemical approach", STP Pharma Sciences, v. 1, pp. 221-41, 1991.

[32] REIS, C.P., VEIGA, F.J., RIBEIRO, A.J., et al., "Nanoparticulate biopolymers deliver insulin orally eliciting pharmacological response”, Journal of Pharmaceutical Sciences, v. 97, n. 12, pp. 5290-5305, 2008.

[33] CHIEN, Y. W., "Human insulin: Basic sciences to therapeutic uses", Drug Development and Industrial Pharmacy, v. 22, n. 8, p. 753-789, 1996.

[34] PAULA, R. C. M., RODRIGUES, J. F., "Composition and rheological properties of cashew tree gum, the exudate polysaccharide from Anacardium occidentale L.", Carbohydrate Polymers, v. 26, pp. 177-181, 1995.

[35] PAULA, R. C. M., HEATLEY, F., BUDD, P.M., "Composition of Anacardium occidentale exsudate polysaccharide”, Polymer International, v. 45, pp. 27-35, 1998.

\section{ORCID:}

Eliadna de Lemos Vasconcelos Silva

Antônia Carla de Jesus Oliveira

Edson Cavalcanti Silva-Filho

Antônio José Ribeiro

Francisco Veiga

Monica Felts de La Roca Soares

Almir Gonçalves Wanderley

José Lamartine Soares Sobrinho https://orcid.org/0000-0002-4168-2269

https://orcid.org/0000-0002-6183-0986

https://orcid.org/0000-0003-0988-2970

https://orcid.org/0000-0002-1399-8944

https://orcid.org/0000-0002-1041-0068

https://orcid.org/0000-0002-4873-915X

https://orcid.org/0000-0001-5193-1153

https://orcid.org/0000-0002-3280-0294 